\title{
ODtimização de substrato de cultivo e características morfoanatômicas de Drosera spathulata
}

\author{
Paula Tristão Santini ${ }^{1}$ \\ Anna Lygia de Rezende Maciel $^{2}$ \\ Ronei Aparecido Barbosa ${ }^{3}$ \\ Amanda Tristão Santini ${ }^{4}$ \\ Roniel Geraldo Ávila5 \\ Kamila Rezende Dázio de Souza ${ }^{6}$
}

\section{Resumo}

A Droseraceaea é uma família de plantas carnívoras, características de solos pobres em nutrientes, úmidos e depauperados, com adaptações para captura e absorção do metabólito de presas, as quais utilizam em seu crescimento e desenvolvimento. As folhas são revestidas, na face adaxial, por estruturas que produzem uma substância mucilaginosa, composta por enzimas proteolíticas, utilizada para aprisionar e digerir eventuais vítimas. Essas plantas possuem ampla distribuição geográfica e estão representadas em quase todas as regiões do mundo. No Brasil, são frequentemente encontradas em floriculturas ou feiras, apesar de serem exigentes em relação ao substrato. A disponibilidade de nutrientes é considerada, de forma geral, o principal fator abiótico que limita a propagação de plantas carnívoras. A carência de trabalhos científicos sobre as espécies de plantas carnívoras associada à dificuldade de adequar o substrato ideal para o seu desenvolvimento e crescimento são os principais motivos para a realização do presente trabalho. Assim sendo, objetivou-se avaliar as características de crescimento e desenvolvimento, bem como as estruturas morfoanatômicas da espécie Drosera spathulata cultivada em diferentes substratos. Como resultado, a fibra de coco proporcionou melhor pegamento das plantas, enquanto maior número de folhas foi obtido utilizando-se a fibra de coco e a mistura de fibra de coco (80\%) e turfa (20\%). As características morfoanatômicas foram parâmetros importantes na classificação da espécie Drosera spathulata.

Palavras-chave: Anatomia vegetal. Droseraceae. Fibra de coco. Turfa.

$1 \quad$ Universidade Federal de Lavras, mestranda em fisiologia vegetal. Lavras, Minas Gerais, Brasil. paulatsantini@gmail.com. (35) 3829-1620. Campus Universitário, Caixa Postal 3037, Lavras, MG, Setor de Fisiologia Vegetal, CEP 37200-000.

2 Instituto Federal de Educação, Ciência e Tecnologia do Sul de Minas Gerais, Campus Muzambinho, professora pesquisadora. (35) 3571-5051, Muzambinho, Minas Gerais, Brasil. anna.lygia@muz.ifsuldeminas.edu.br. Estrada de Muzambinho, Km 35- Bairro Morro Preto - Caixa Postal 02, CEP 37890-000.

3 Instituto Federal de Educação, Ciência e Tecnologia do Sul de Minas Gerais, Campus Muzambinho, pesquisador. Muzambinho, Minas Gerais, Brasil. barbosavip@hotmail.com. (35) 3571-5051. Estrada de Muzambinho, Km 35 - Bairro Morro Preto - Caixa Postal 02, CEP 37890-000.

4 Instituto Federal de Educação, Ciência e Tecnologia do Sul de Minas Gerais, Campus Muzambinho, graduanda em ciências biológicas. Muzambinho, Minas Gerais, Brasil. amanda_tsantini@yahoo.com.br. (35) 3571-5051. Estrada de Muzambinho, Km 35 - Bairro Morro Preto - Caixa Postal 02, CEP 37890-000.

$5 \quad$ Universidade Federal de Lavras, mestrando em fisiologia vegetal. Lavras, Minas Gerais, Brasil. ronielgeraldo@yahoo.com.br. (35) 3829-1620. Campus Universitário, Caixa Postal 3037, Lavras/MG, Setor de Fisiologia Vegetal, CEP 37200-000.

$6 \quad$ Universidade Federal de Lavras, doutoranda em fisiologia vegetal. Lavras, Minas Gerais, Brasil. krdazio@hotmail.com. (35) 38291620. Campus Universitário, Caixa Postal 3037, Lavras/MG, Setor de Fisiologia Vegetal, CEP 37200-000. 


\section{Introdução}

As plantas carnívoras, apesar de apresentarem nutrição autotrófica obrigatória, desenvolveram adaptações para capturar presas, absorver seus metabólitos e utilizá-los em seu crescimento e desenvolvimento (ALDENIUS et al., 1983). Esses organismos possuem ampla distribuição geográfica, estando representados em quase todas as regiões do mundo, em habitats caracterizados por apresentarem solos pobres em nutrientes, úmidos e depauperados, adequados, assim, à propriedade de se nutrirem diretamente de animais para sobreviverem sob condições adversas (FIRMINO et al., 2000).

A família Droseraceae caracteriza-se por espécies herbáceas, com caules curtos ou acaules, rizomas alongados, abreviados ou bulbosos, com folhas alternadas, dispostas em roseta, simples ou com estípulas, cobertas de glândulas e tricomas, formando assim uma armadilha para o inseto (SARIDAKIS et al., 2004). Trata-se de folhas modificadas capazes de capturar, prender e digerir, por ação enzimática, alguns animais. Essas folhas armadilhas atuam na atração, digestão e assimilação das presas (TAVARES, 2009) e, para tanto, são revestidas, na face adaxial, por tricomas glandulares (RAVEN et al., 1996), os quais produzem uma substância mucilaginosa, composta por enzimas proteolíticas. De fato, essa mucilagem, juntamente com a cor e o aroma característicos da Drosera, é responsável pela atração da presa (PILIACKAS et al., 1999).

Os tricomas glandulares apresentam um pedúnculo multicelular e uma cabeça envolvida por três a quatro camadas de células cobertas por cutícula, perfurada na região das células glandulares. No interior desse pedúnculo, existe um feixe de traqueides envolvido por uma camada endodérmica, com células portadoras de estrias de Caspary (CUTTER, 1986). Para Juniper et al. (1989), os tricomas glandulares de Drosera estão envolvidos no transporte de fluido digestivo e constituem formas primitivas de glândula digestiva eficientes no aprisionamento e digestão de artrópodes.

A disponibilidade de nutrientes é considerada, de forma geral, o principal fator abiótico que limita a propagação de plantas carnívoras (ZAMORA et al., 1998). O substrato deve ter consistência para suporte, boa aeração, permeabilidade, poder de tamponamento para valor de $\mathrm{pH}$, capacidade de retenção de nutrientes e reidratação após a secagem; deve ainda apresentar alta estabilidade de estrutura, alto teor em fibras resistentes à decomposição e estar isento de agentes causadores de doenças, pragas e propágulos de ervas daninhas (ARAúJO; LEMOS, 2004).

A utilização da fibra e do pó de coco vem se destacando como um dos mais promissores substratos alternativos ao xaxim, tanto para culturas agronômicas quanto para ornamentais (CARRIJO et al., 2002). Suas potencialidades de uso na composição de substrato agrícola estão relacionadas com a capacidade de retenção de água, boa drenagem, acidez, alta salinidade - decorrente, sobretudo, dos altos teores de potássio e cloro - e variação nos teores de nutrientes. Pesquisas sobre o cultivo de diferentes espécies de plantas ornamentais com uso da fibra, pura ou em mistura, têm mostrado seu desempenho superior a outros substratos (ABAD, 2005).

Outro tipo de substrato muito utilizado é a turfa, um mineral formado nos últimos dez mil anos, resultante do atrofiamento e da decomposição incompleta de material lenhoso e de arbustos, musgos e liquens em condições de umidade excessiva. Dessa forma, a turfa está associada a zonas pantanosas ou encharcadas e constitui uma suspensão quase coloidal de 80 a $85 \%$ de água (GAULAND, 1997). 
As Droseraceae são plantas requisitadas para ornamentação e paisagismo, frequentemente encontradas em floriculturas ou feiras. No entanto, há dificuldade de adequação do substrato ideal para a sua propagação e registra-se, ainda, a carência de estudos científicos acerca de plantas carnívoras. Dessa maneira, o presente estudo teve como objetivos avaliar a eficiência de diferentes substratos na propagação de Drosera spathulata e caracterizar morfoanatomicamente essa espécie.

\section{Material e métodos}

O material vegetal utilizado foi obtido de espécimes cultivados de Drosera spathulata via propagação sexuada. 0 experimento foi mantido em casa de vegetação com umidade relativa em torno de $85 \pm 5 \%$.

Os tratamentos foram os seguintes: T1: fibra de coco; T2: turfa (80\%) + fibra de coco (20\%); T3: turfa $(80 \%)+$ Plantmax $^{\circledast}$ (substrato comercial para cultivo de plantas) (20\%); e T4: fibra de coco $(80 \%)+$ turfa $(20 \%)$.

As avaliações foram realizadas 120 dias após a instalação do experimento. Determinaram-se o número de folhas, as características morfoanatômicas e a porcentagem de pegamento (número de plantas emergidas).

Para os estudos morfoanatômicos, utilizaram-se plantas de Drosera spathulata cultivadas em fibra de coco (T1). Realizaram-se cortes transversais manuais de raízes, pecíolos e folhas. As secções foram clarificadas em solução de hipoclorito de sódio a 1,25\%. Em seguida, foram neutralizadas em ácido acético na proporção de 1:500 e coradas com corante Safrablau (Safranina e Azul de Astra) (BUKATSCH, 1972). As características morfoanatômicas foram registradas por meio de fotomicroscópio óptico (Nikon, Modelo Eclipse-E 200, China).

Os dados foram submetidos ao teste de Shapiro-Wilk (1965) para a verificação de sua normalidade; sendo eles considerados paramétricos, posteriormente foram submetidos ao teste de Scott-Knott. 0 delineamento experimental utilizado foi em blocos casualizados, com 5 repetições e 5 vasos por parcela, com 4 plantas por vaso. Os dados obtidos foram submetidos à análise de variância, utilizando-se o programa estatístico SISVAR 4.3 (FERREIRA, 2011). As médias obtidas foram comparadas pelo teste de Scott-Knott, adotando-se os níveis de significância de $P \leq 0,01$.

\section{Resultados e discussão}

Plantas de Drosera spathulata cultivadas em fibra de coco apresentaram elevada porcentagem de pegamento quando comparadas àquelas cultivadas nos demais substratos (Figura 1). Os substratos contendo turfa como componente principal apresentaram a menor porcentagem de pegamento das plantas, em razão da alta concentração de nutrientes presentes na turfa, não sendo vantajoso a esse tipo de espécie. 0 substrato com fibra de coco favoreceu o ambiente para germinação das sementes de Drosera spathulata por atender às necessidades de um bom substrato para produção de mudas. O substrato deve proporcionar retenção de água suficiente para permitir a germinação e, quando saturado (em excesso de água), deve manter quantidades adequadas de espaço poroso para facilitar o fornecimento de oxigênio, indispensável para o processo de germinação e desenvolvimento radicular (SMIDERLE; MINAMI, 2001) 


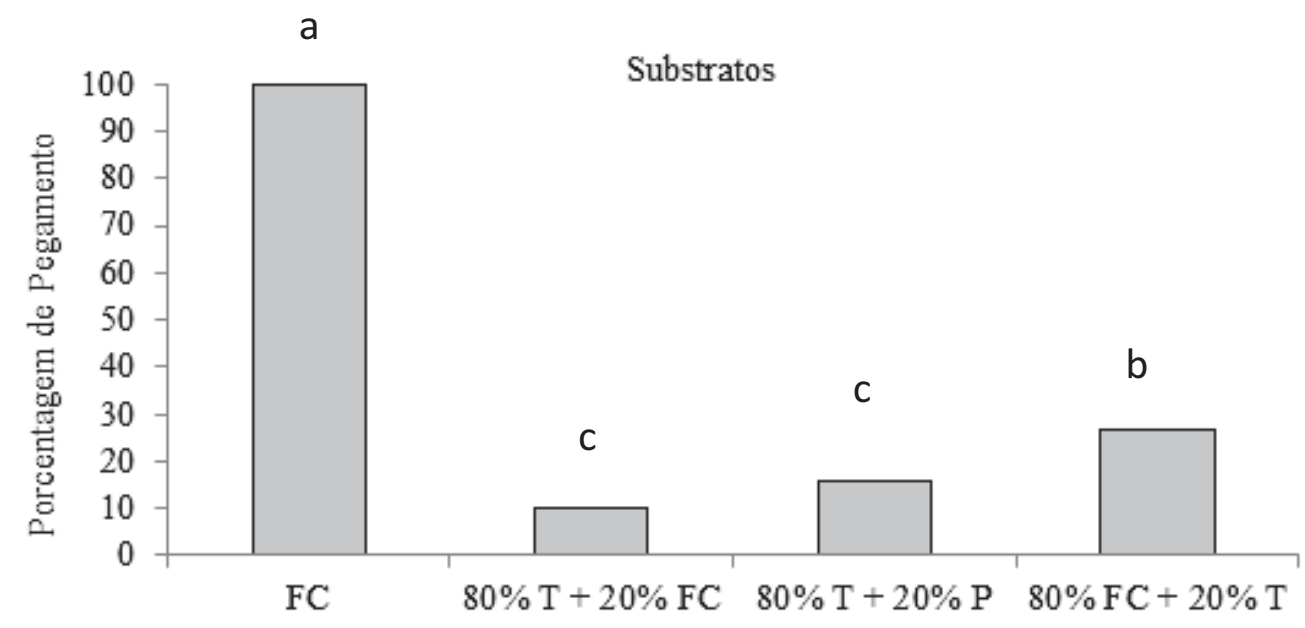

Figura 1. Porcentagem de pegamento de plantas de Drosera spathulata cultivadas em diferentes substratos (FC: fibra de coco, T: turfa e P: Plantmax ${ }^{\circledR}$ ). As médias foram comparadas pelo teste de Scott- Knott ao nível de $\mathrm{P} \leq 0,01$ de probabilidade.

Fonte: Elaboração dos autores.

As plantas cultivadas nos substratos fibra de coco e na mistura entre a fibra de coco $(80 \%)$ e a turfa (20\%) apresentaram maior número de folhas (Figura 2). Esses resultados podem ter sido favorecidos pela boa aeração e drenagem que os substratos à base de coco propiciaram às plantas (ASSIS et al., 2008). Essa circunstância, possivelmente, aumenta a disponibilidade de água e oxigênio $\left(\mathrm{O}_{2}\right)$, favorecendo a respiração e, consequentemente, o aumento na produção de energia que poderia favorecer o desenvolvimento das gemas vegetativas (foliares). Além disso, o aumento da taxa respiratória contribuiu para os processos de síntese e manutenção do metabolismo celular (SAQUET et al., 2000).

Resultados semelhantes foram obtidos por Demattê (2001) que, estudando a espécie Tillandsia gardeni Lindl. (Bromeliaceae), observou que misturas contendo fibra de coco em sua composição proporcionaram maior número de folhas, inflorescências e brotações às plantas.

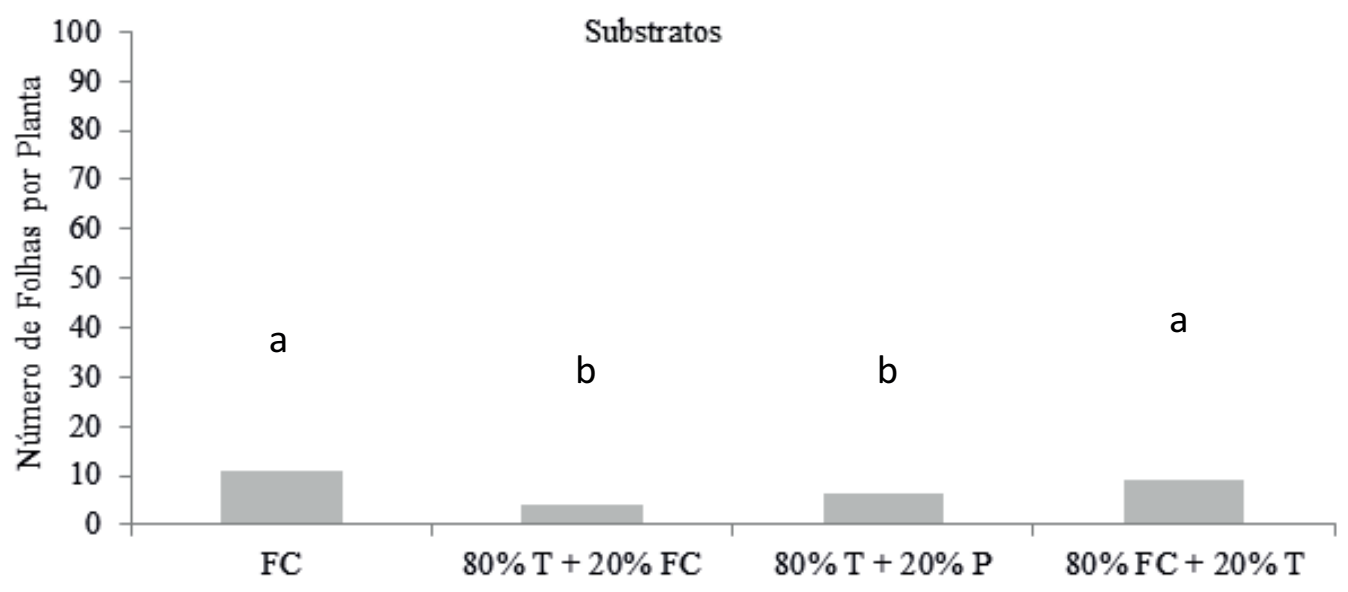

Figura 2. Número de folhas por plantas de Drosera spathulata cultivadas em diferentes substratos (F:fibra de coco, T: turfa e P: Plantmax ${ }^{\circledR}$ ). As médias foram comparadas pelo teste de Scott-Knott ao nível de $P \leq 0,01$ de probabilidade.

Fonte: Elaboração dos autores. 
As características básicas e indispensáveis de um substrato são: alta estabilidade de estrutura, alto teor em fibras resistente à decomposição e isenção de agentes causadores de doenças, pragas e propágulos de ervas daninhas. Além disso, deve apresentar consistência para suporte, boa aeração, permeabilidade, poder de tamponamento para valor de $\mathrm{pH}$, capacidade de retenção de nutrientes e reidratação após a secagem (ARAÚJO, 2004).

Existe grande potencial no uso de fibra de coco como substrato agrícola para o desenvolvimento de espécies vegetais cultivadas e o bom desempenho constatado nesse substrato pode dever-se a várias características, das quais se destacam a capacidade de retenção de água, a boa drenagem, a alta salinidade - decorrente, sobretudo, dos altos teores de potássio e cloro - e a variação nos teores de nutrientes (CARRIJO et al., 2002).

As folhas de plantas de Drosera spathulata adultas são anfiestomáticas e a epiderme, em vista frontal, é formada por células alongadas nas duas superfícies, com estômatos anomocíticos (MIRANDA; SAJO, 2000).

Em corte transversal, as folhas mostram epiderme uniestratificada, mesofilo homogêneo lacunoso e vários feixes vasculares colaterais (Figura 3). De cada feixe partem cordões de traqueídeos que suprem os tricomas (MIRANDA; SAJO, 2000).

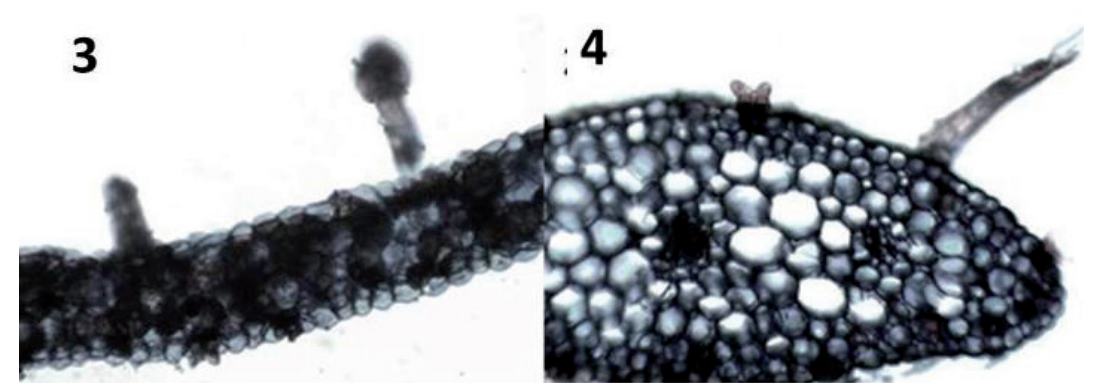

Figura 3. Fotomicrografia de seção transversal de folha de Drosera spathulata. Instituto Federal do Sul de Minas - Campus Muzaminho. Muzambinho/MG. 2013.

Figura 4. Fotomicrografia de seção transversal de pecíolo de Drosera spathulata. Instituto Federal do Sul de Minas - Campus Muzaminho. Muzambinho/MG. 2013

Fonte: Elaboração dos autores.

A Figura 4 mostra o pecíolo que, em corte transversal, apresenta epiderme uniestratificada com estômatos em toda a superfície e parênquima lacunoso envolvendo três feixes vasculares.

Em Drosera spathulata, os tricomas tectores e glandulares ocorrem nas lâminas, pecíolos e emergências glandulares de diferentes tipos.

Os tricomas glandulares de Drosera spathulata estão envolvidos no transporte de fluido digestivo (JUNIPER et al., 1989). Entretanto, como na secreção das emergências ocorrem mucilagem e enzimas, eficientes no aprisionamento e digestão dos insetos (JUNIPER et al., 1989), a presença de outras glândulas digestivas parece ser desnecessária.

A Drosera spathulata possui sistema radicular fasciculado sem a presença de raiz primária. Após os 120 dias de condução do experimento, essa planta carnívora apresentava sistema radicular formado por inúmeras raízes adventícias. Após a emergência, as plântulas desenvolvem pelos epidérmicos unicelulares, na base do hipocótilo, que atingem grande comprimento e cuja função vai além da de absorção de água e nutrientes. Os pelos apresentam paredes delgadas, observando-se muitas vezes um dobramento na base, próximo à epiderme, que pode ser confundido com parede celular. 
Crescem em direção ao substrato e, ao atingi-lo, cessam o crescimento. Dessa forma, a planta é ancorada e sustentada verticalmente (MIRANDA; SAJO, 2000). No ápice dos pelos, na região de contato com o substrato, aparecem dilatações que funcionam como apressórios, promovendo maior eficiência na fixação da planta.

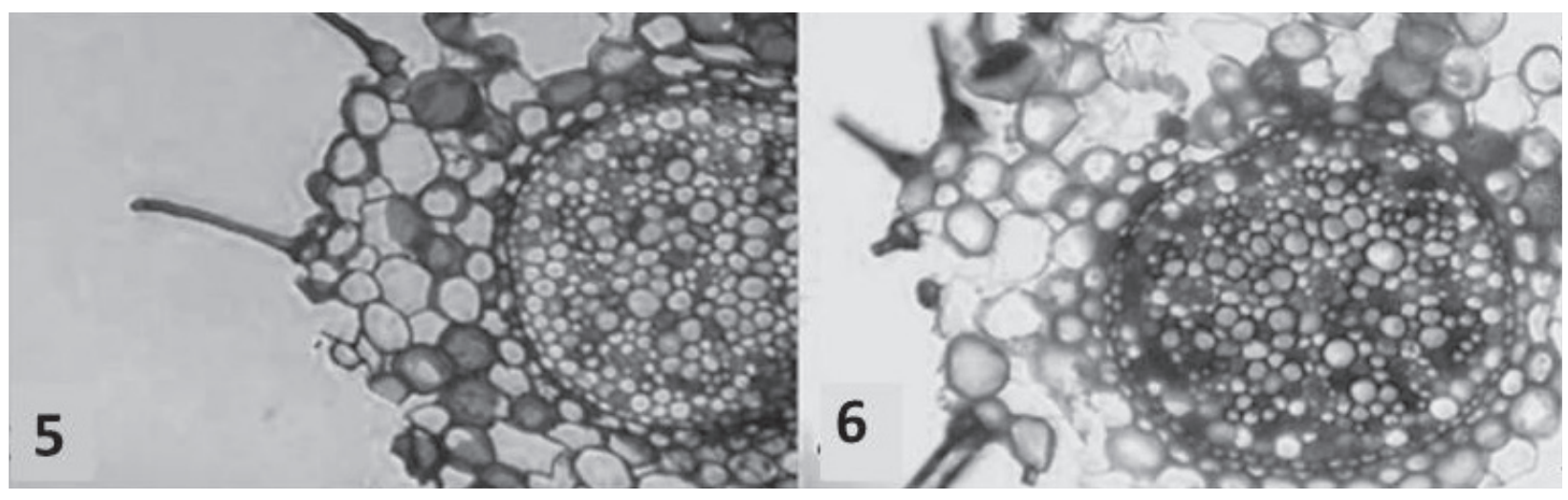

Figuras 5 e 6. Fotomicrografias de seções transversais de raiz de Drosera spathulata. Instituto Federal do Sul de Minas - Campus Muzambinho. Muzambinho/MG. 2013.

Fonte: Elaboração dos autores.

\section{Conclusões}

Nas condições em que o presente trabalho foi realizado, pode-se concluir que a fibra de coco proporciona o melhor pegamento das plantas. O maior número de folhas é obtido utilizando-se como substratos a fibra de coco e a mistura entre fibra de coco (80\%) e turfa (20\%), levando em conta também que a fibra de coco é um susbstrato mais acessível para se trabalhar com cultivo de plantas. As características morfoanatômicas são parâmetros importantes na classificação da espécie Drosera spathulata.

\section{Optimization of Drosera spathulata culture substrate and morphoanatomic characteristics}

\section{Abstract}

Droseraceaea belong to carnivorous plants family, characteristic of poor nutrient, wet and depleted soils, with adaptations to capture prey, absorb its metabolites and use them in their growth and development. On their adaxial faces, the leaves are coated by structures that produce a mucilaginous substance, composed by proteolytic enzymes, used to trap and digest any victims. These plants have a wide geographical distribution, being represented in almost all regions of the world. In Brazil, they are often found in flower shops or fairs despite being choosy about substrate. The availability of nutrients is considered, in general, the main abiotic factor that limits the spread of carnivorous plants. The lack of scientific research on species of carnivorous plants associated with the difficulty of fitting the ideal substrate for their development and growth are the main reasons for carrying out this work. Thus, we aimed to evaluate the characteristics of growth and development as well as the structures of morphoanatomic Drosera spathulata species grown on different substrates. As a result, coconut fiber provided better fixation of the plants, while larger number of leaves was obtained by using the coconut 
fiber and a mixture of coconut fiber (80\%) and peat (20\%). Morphoanatomical characteristics were important parameters in the classification of Drosera spathulata species.

Keywords- Plant anatomy. Droseraceae. Coconut fiber. Peat.

\section{Referências}

ABAD, M. Los sustratos hortícolas y técnicas de cultivo sin suelo. In: RALLO, L., NUEZ. F. (Eds.). La horticultura Española en la C.E. Reus: Horticultura S.L, p.271- 280, 2002.

ALDENIUS, J; CARLSSON, B.; KARLSSON, S. Effects of insect trapping on growth and nutrient content of Pinguicula vulgaris $L$. in relation to the nutrient content of the substrate. New Phytologist. v.93, p.53-60, 1983.

ARAÚJO, R., LEMOS, P. Plantas Carnívoras ocorrentes na Cachoeira Sempre-Viva do Parque Estadual do Rio Preto (PERP), MG. Revista Brasileira de Biociências, Porto Alegre, v.5, suplemento 2, p.687689. 2004.

ASSIS, R. N.; HERNANDEZ, F. F. F.; OLIVEIRA, A. B. Pó de coco verde, uma alternativa de substrato na produção de mudas de berinjela. Revista Ciência Agronômica. Fortaleza, v.39, n.1, p.39-44, 2008.

BUKASTCH, F. Bermerkungen zur doppelfarbung astrablau-safranina. Microkosmos. v. 61, n.8,. p.61-255, 1972.

CARRIJO, O. A. LIZ, R. S.; MAKISHIMA, N. Fibra de coco verde como substrato agrícola. Horticultura Brasileira, Brasília, v.20, n.4. p.533-535, 2002.

CUTTER, E. G. Anatomia vegetal. Parte I - Células e Tecidos. São Paulo: Livraria Rocca Ltda, 1986.

DEMATTÊ, M. E. S. P. Cultivo de Tillandsia gardneri Lindl. em diferentes substratos. In: CONGRESSO BRASILEIRO DE FLORICULTURA E PLANTAS ORNAMENTAIS, 13, 2001, São Paulo. Anais... São Paulo: SBFPO, 2001. p.118.

FERREIRA, D. F. Sisvar, a computer statistical analysis system. Ciência e Agrotecnologia, Lavras, v.35, n.6, p.1039-1042, 2011.

FIRMINO, M. H.; TRENTIN, A. L.; KAMPF, A. N. Caracterização física e química de materiais alternativos para composição de substratos para plantas: 1. Resíduos industriais e agrícolas. In: KÄMPF, A.N.; FERMINO, M.H. (Eds.). Substratos para plantas: a base da produção vegetal em recipientes. Porto Alegre: Genesis, 2000. p.241-248.

GAULAND, D. C. S. P. Relações hídricas em substratos à base de turfas sob uso das condicionadores casca de arroz carbonizada ou queimada. 1997, 107 f. Dissertação (Mestrado em Ciência do Solo) - Universidade Federal do Rio Grande do Sul, Porto Alegre.

JUNIPER, B. E., ROBINS R. J.; JOEL, D. M. The carnivorous plants. London: Academic Press, 1989.

MIRANDA, V. F. O.; SAJO, M. G. Aspectos morfo-anatômicos de três espécies de drosera durante o desenvolvimento pós-seminal. Acta Botânica Brasileira. v.14, n.2, p.185-195. 2000. 
PILIACKAS, J. M.; BARBOSA, L. M.; BARBOSA, J. M. Plantas carnívoras - influência dos fatores bióticos e abióticos. Ecossistema. Espírito Santo do Pinhal, SP v.14, p. 69-76, 1999.

RAVEN, P. H.; EVERT, R. F.; EICHOORN, S. E. Biologia vegetal. Rio de Janeiro: Editora Guanabara Koogan S.A., 1996.

SARIDAKIS, D. P. Análise taxonômica e ecológica das plantas carnívoras da bacia do rio Tibagi-PR. 2004. Monografia, Universidade Estadual de Londrina, Londrina, Paraná, Brasil.

SAQUET, A.A.; STREIF, J.; BANGERTH, F. Changes. in ATP, ADP and pyridine nucleotide levels related to the incidence of physiological disorders in 'Conference' pears and 'Jonagold' apples during controlled atmosphere storage. Journal of Horticultural Science \& Biotechnology, v.75, p.243-249, 2000.

SHAPIRO, S. S., WILK, M. B. An analysis of variance test for normality (complete samples). Biometrika, n.52, p.591-611, 1965.

SMIDERLE, O.S.; MINAMI, K. Emergência e vigor de plântulas de goiabeira em diferentes substratos. Revista Científica Rural, Bagé. v.6, n.1, p.38-45, 2001.

TAVARES, A. C. P. Plantas Carnívoras. Departamento de Botânica. Universidade de Coimbra, Coimbra, 2009.

ZAMORA, R.; GOMEZ, J. M.; HÓDAR, J. A. Fitness responses of a carnivorous plant in contrasting ecological scenarios. Ecology, n.79, p.1630-1644, 1998.

\section{Histórico editorial}

Submetido em: 13/05/2014

Aceito em: 26/11/2014 